\title{
Visible Light Induced Enhanced Photocatalytic Degradation of Industrial Effluents (Rhodamine B) in Aqueous Media Using $\mathrm{TiO}_{2}$ Nanoparticles
}

\author{
J. O. Carneiro, ${ }^{1,2}$ A. P. Samantilleke, ${ }^{1}$ P. Parpot, ${ }^{3}$ F. Fernandes, ${ }^{1}$ M. Pastor, ${ }^{1}$ \\ A. Correia, ${ }^{1}$ E. A. Luís, ${ }^{2}$ A. A. Chivanga Barros, ${ }^{2}$ and V. Teixeira ${ }^{1}$ \\ ${ }^{1}$ Centre of Physics, University of Minho, Azurém Campus, 4800-058 Guimarães, Portugal \\ ${ }^{2}$ Instituto Superior Politécnico de Tecnologias e Ciências, Avenida Luanda Sul, Rua Lateral Via S10, Talatona, \\ Município de Belas, Luanda, Angola \\ ${ }^{3}$ Centre of Chemistry, University of Minho, Gualtar Campus, 4710-057 Braga, Portugal
}

Correspondence should be addressed to J. O. Carneiro; carneiro@fisica.uminho.pt and A. P. Samantilleke; anura@fisica.uminho.pt

Received 13 September 2015; Revised 15 January 2016; Accepted 18 January 2016

Academic Editor: Abdelwahab Omri

Copyright (C) 2016 J. O. Carneiro et al. This is an open access article distributed under the Creative Commons Attribution License, which permits unrestricted use, distribution, and reproduction in any medium, provided the original work is properly cited.

In recent years, new textile materials have been developed through the use of nanotechnology-based tools. The development of textile surfaces with self-cleaning properties has a large combined potential to reduce the environmental impact related to pollution. In this research work, three types of textiles substrates (cotton, Entretela, and polylactic acid (PLA)) were functionalized with titanium dioxide nanoparticles $\left(\mathrm{TiO}_{2}\right)$ using chemical and mechanical processes (padding). During the functionalization process, two different methods were used, both of which allowed a good fixation of nanoparticles of $\mathrm{TiO}_{2}$ on textile substrates. The samples were examined for morphology and for photocatalytic properties under visible light irradiation. A study aimed at evaluating the effect of $\mathrm{pH}$ of the aqueous solution of $\mathrm{TiO}_{2}$ nanoparticles was performed in order to promote interaction between $\mathrm{TiO}_{2}$ and the dye solution rhodamine $\mathrm{B}(\mathrm{Rh}-\mathrm{B})$. The $\mathrm{TiO}_{2}$ nanoparticles were characterized by X-ray diffraction (XRD). The measurement of the zeta potential of the $\mathrm{TiO}_{2}$ nanoparticle solution proved to be always positive and have low colloidal stability. Chromatography (HPLC and GC-MS) analyses confirm that oxalic acid is the intermediate compound formed during the photodegradation process.

\section{Introduction}

During recent decades, environmental pollution has threatened the survival of life on Earth as never before [1-3]. Water is one of the most essential substances for the life's existence on Earth [4]. With the increasing demand for drinking water due to exponential increase of the world population, it is expected that only $60 \%$ of the drinking water worldwide will be met by $2030[2,5]$.

Prominent among all phenomena that cause pollution is the release of contaminated waste waters and particularly that released by different social segments. Major sources of water contamination include removal of recalcitrant organic pollutants, such as organic dyes and pesticides and antibiotics, which seriously affect the quality of the hydric resources and human health $[4,6]$. Dyes, which are an abundant class of coloured organic compounds, are found in wastewaters due to the large scale of industrial production, slow biodegradation, and toxicity $[4,7-9]$. It is estimated that up to $20 \%$ of the total world production of dyes is lost during synthesis and colouration processes $[6,10]$. Rhodamine $B(R h-B)$ represents one of the most important dyes, extensively used in the textile industry due to its high stability. Its release into the environment is dangerous for aquatic life as in many cases; it is carcinogenic and mutagenic for both humans and animals. Thus, decomposition of such organic dyes is significantly 
important for the purification and conservation of water $[1,4,11]$.

The treatment of wastewater has to be simple (easy to control and maintain experimental conditions), efficient, environmentally friendly, easy to be applied, and also of low cost $[11,12]$. Traditional efficient technologies used for this purpose such as biological, physical, and chemical methods contain limitations because of the low efficiency of degradation, chemical consumption, and creation of secondary pollutants $[1,6,9,11]$. In order to overcome such disadvantages, new scientific approaches have been developed in order to integrate advanced oxidation processes (AOP) as alternative to traditional technologies. Such processes are based on the generation of highly reactive species (hydroxyl radical) to oxidize quickly and in nonselectively a wide range of organic pollutants $[6,7,9,10]$. One of these processes, considered very promising and effective, is called heterogeneous photocatalysis, which, by combining a source of ultraviolet (UV) light and a semiconductor, promotes the degradation of pollutants from wastewater, converting them into water $\left(\mathrm{H}_{2} \mathrm{O}\right)$ and carbon dioxide $\left(\mathrm{CO}_{2}\right)[7,9,10,13]$. The use of semiconductor materials makes the process cheaper and additionally these materials enable easy mineralization of many organic compounds without the need of using additives [13]. Among them, $\mathrm{TiO}_{2}$, in particular nanoscale $\mathrm{TiO}_{2}$, has a high photocatalytic activity, is inexpensive in the market, is abundant, and possesses high chemical stability and nontoxicity $[10,14-17]$. However, the release of $\mathrm{TiO}_{2}$ nanoparticles in the environment potentially could lead to negative impacts on human health and ecosystems. On the other hand, introducing steps of separation or recovery of $\mathrm{TiO}_{2}$ nanoparticles is often necessary, when using certain biological processes $[4,7,18]$. Therefore, it is essential to opt for a strategy that immobilizes $\mathrm{TiO}_{2}$ nanoparticles on different materials in order to avoid the already identified deficiencies. Several attempts have been made to immobilize $\mathrm{TiO}_{2}$ nanoparticles on various media including glass, stainless steel, alumina, activated carbon, concrete surfaces, asphalt road pavements, zeolites, and silica gel by different coating techniques $[4,7,9$, 17-19]. Currently, textile substrates are employed in various technological areas including nanotechnology approaches due to their high flexibility. In fact, given its low weight, low mechanical stiffness, and workability, $\mathrm{TiO}_{2}$ functionalized textile substrates can be easily applied and adapted on surfaces with nonregular geometry that often exist in reactors for wastewater treatment, without the need to change the layouts already installed. The main goal of the present research work was the evaluation of the Rh-B photocatalytic degradation efficiency promoted by $\mathrm{TiO}_{2}$ functionalized textile substrates by using two different functionalization processes.

\section{Experimental}

\subsection{Materials and Methods}

2.1.1. Chemicals. $\mathrm{TiO}_{2}$ nanoparticles (Aeroxide $\mathrm{TiO}_{2} \mathrm{P} 25$ ) were purchased from Quimidroga (Spain), while potassium hydroxide $(\mathrm{KOH})$ and Rh-B were purchased from SigmaAldrich (Portugal). A solution of $\mathrm{TiO}_{2}$ nanoparticles $20 \mathrm{~g} / \mathrm{L}$

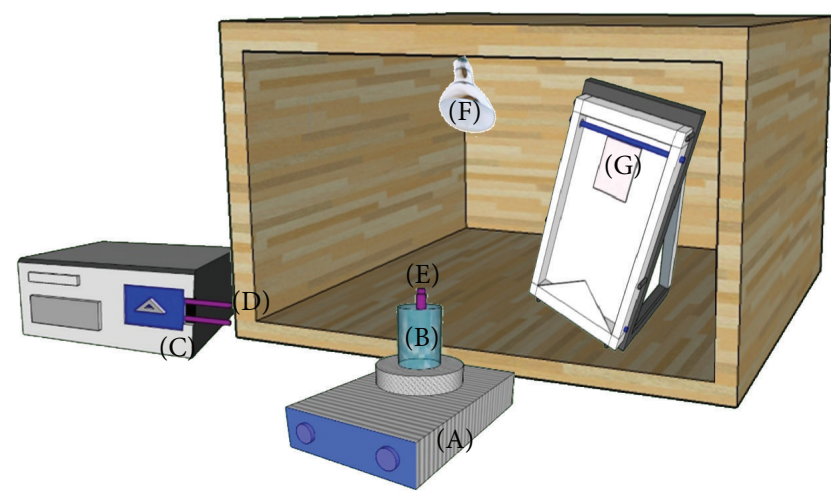

FIGURE 1: Schematic diagram of the experimental setup: (A) stirrer/hotplate; (B) dye reservoir; (C) peristaltic pump; (D) feeding from pump; (E) flow to beaker; (F) visible light lamp; (G) catalyst substrate.

was prepared in deionised water. The wetting solution Diadavin ANE (nonionic) was obtained from ADI Group. PLA, Entretela, and cotton are characteristic and specific terms used in the field of textile industry and their meanings can be accessed in a textile glossary [17].

2.1.2. Photocatalytic Reactor. The experimental setup for degradation of $\mathrm{Rh}-\mathrm{B}$ consists of a recirculation photocatalytic reactor with a $37^{\circ}$ slanted stainless steel plate having a working area of $30 \times 30 \mathrm{~cm}^{2}$ and a homemade Teflon reservoir with dimensions of $24 \times 24 \mathrm{~cm}^{2}$ placed on the stainless steel plate. A $400 \mathrm{~mL}$ dye solution with an initial concentration of $4 \mathrm{mg} / \mathrm{L}$ was prepared in deionised water in the reservoir, maintained under agitation during the entire operation time, and continuously circulated in the system by a peristaltic pump at a constant flow rate of $130 \mathrm{~mL} \cdot \mathrm{min}^{-1}$, enabling optimal distribution of the liquid over the catalytic Teflon reservoir, as schematically shown in Figure 1. Hereinafter, this condition will be referred to as dynamic regime. Following this procedure, we have waited long enough to allow the textile substrates to absorb (in the dark) stain.

Visible light irradiation was provided by using one lamp emitting light with a wavelength between 250 and $800 \mathrm{~nm}$, with a greater intensity near $365 \mathrm{~nm}$. Visible light irradiation was provided by a lamp with the strongest emission at wavelength $365 \mathrm{~nm}$ (Ultra Vitalux, $300 \mathrm{~W}$; OSRAM), placed at a distance of about $20 \mathrm{~cm}$ above the sample's surface. The average irradiance was around $40 \mathrm{~W} \cdot \mathrm{m}^{-2}$ (measured with a visible light irradiation Meter LTLutron YK-35UV). The absorbance of the Rh-B was monitored over a period of $420 \mathrm{~min}$ (at time intervals of $40,80,120,180,240,300,360$, and $420 \mathrm{~min}$ ) using a spectrophotometer (ScanSpec UV-Vis, ScanSci) in the range of 300-700 nm. For this, some aliquots of Rh-B solution $(3.5 \mathrm{~mL})$ were taken out and analyzed by monitoring the intensity variation of its main absorption peak (around $564 \mathrm{~nm}$ ). The influence of visible light irradiation over the dye's degradation was also evaluated, that is, in the absence of $\mathrm{TiO}_{2}$. The reactor was washed after every run by circulating deionised water during 10 minutes and alcohol for another 10 minutes. 
(i) Immersing the textile substrate in the wetting solution

(i) Immersing the textile substrate in titanium dioxide solution

(i) Padding the textile substrate

(i) Drying the textile substrate in the oven for 24 hours

FIGURE 2: Description of functionalization steps with wetting solution.

2.1.3. Functionalization of Textile Substrate. Two different methods were used in performing the functionalization of textile substrates.

Method 1: Wettability and Functionalization of Textile Substrates. Two different solutions, namely, a wetting solution and $\mathrm{a} \mathrm{TiO}_{2}$ solution $\left(20 \mathrm{~g} \cdot \mathrm{L}^{-1}\right)$, were used in this method. The wetting solution comprised distilled water and a nonionic surfactant (Diadavin ANE), consisting of $10 \%$ of the total weight of the textile substrate.

Upon completion of wash step, the functionalization process is described according the sequence shown in Figure 2.

This process is repeated four times.

Method 2: Functionalization of Textile Substrates by Using a Surface Modifier (KOH). The textile substrates were immersed in a $\mathrm{KOH}(0.3 \mathrm{M})$ aqueous solution in order to increase the amount of $\mathrm{OH}^{-}$groups on the substrate surface. The same $\mathrm{TiO}_{2}$ nanoparticle solution was used in both methods. The process description is shown in the following scheme (Figure 3).

Once again, the process is repeated four times.

Washing Process after Photodegradation. The washing processing was carried out (according to the Standard ISO 105 C06- $\mathrm{N}^{\circ}$ A1S) in order to evaluate the adhesion of $\mathrm{TiO}_{2}$ nanoparticles on the surface of textiles substrates. Under the occurrence of an eventual scenario, characterized by a significant decrease in photocatalytic efficiency, the $\mathrm{TiO}_{2}$ adhesion on the surface of textile substrates has to be weak. In the present work, a conventional washing machine was used (FE Lupton Ltd., England) under a laundering bath temperature of $60^{\circ} \mathrm{C}$ for 20 minutes. The substrates were placed in a test-tube with a washing solution prepared by dissolving $10 \%$ of substrate mass of Diadavin ANE in $200 \mathrm{~mL}$ of distilled water. The laundering cycle was repeated 5 times. The samples drying was made at room temperature. These samples were named "after-washing" throughout the paper.

The structure, morphology, optical, electrical, photocatalytic, and chemical properties of the produced samples were investigated by using X-ray diffraction (XRD), scanning electron microscopy (SEM), Energy Dispersive X-Ray

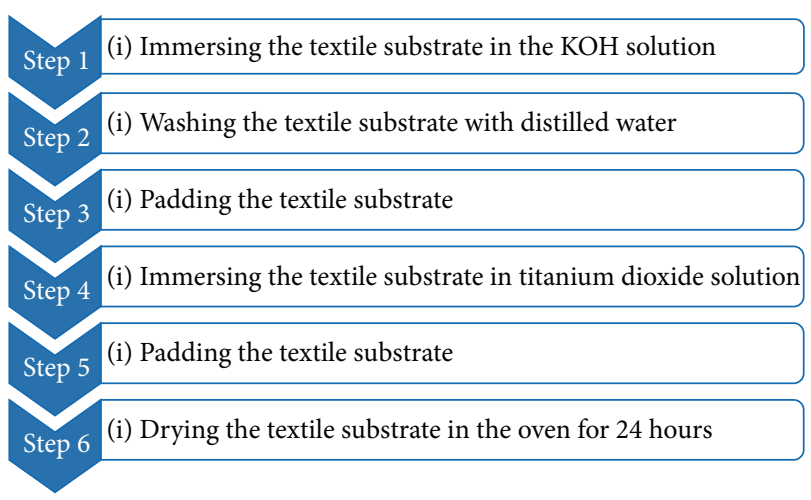

FIGURE 3: Description of functionalization steps with $\mathrm{KOH}$ solution.

Spectroscopy (EDX), contact angle, zeta potential, absorption spectra, and chromatography, respectively.

$X R D$ was employed to investigate the crystal structure and the crystallite size of the nanoparticles was estimated by applying the Debye-Scherrer equation [20]:

$$
D_{h k l}=\frac{0.94 \times \lambda}{B_{h k l} \times \cos \theta} .
$$

Here, $D_{h k l}$ is the mean grain size with crystalline planes $(h k l), B_{h k l}$ is the WHPM intensity in radians, and $\lambda$ is the wavelength of the $\mathrm{CuK}_{\alpha}$ radiation source.

The morphology of textile substrates was examined using scanning electron microscopy (SEM, NanoSEM FEI Nova 200). The elemental composition of textiles substrates was analyzed by EDX in the SEM instrument.

Absorption spectra were acquired by using a Shimadzu 3101 PC spectrophotometer. The spectra were recorded at room temperature in air within the range of 300-700 nm.

Contact angle measurement allowed evaluation of the surface wettability in a dynamic mode using Young La Place method (Contact Angle System SA data physics) with distilled water droplets $(5 \mu \mathrm{L} / \mathrm{s})$. The contact angle (CA) formed by water on samples surfaces was measured in order to assess the wettability of textile substrates.

Chromatography analyses were performed on high performance liquid chromatography (Pump: Jasco PU-2080 Plus-Intelligent HPLC Detector: Jasco UV-870-Intelligent UV/VIS) in two different columns and ion chromatography (IC). A Grace Smart (RP $185 \mu \mathrm{m}, \lambda=564 \mathrm{~nm}$ ) column and an Aminex HPX-87H (30 cm, RI: Jasco, $\lambda=210 \mathrm{~nm})$ column were used. The following solvent systems were used as mobile phase: solvent A and solvent B (acetic acid/sodium acetate $(1: 1))$, buffer $\mathrm{pH} 5$. Compounds were eluted at a flow rate of $0.6 \mathrm{~mL} / \mathrm{min}$ and at room temperature.

\section{Results and Discussion}

3.1. Structural Analysis. $\mathrm{TiO}_{2}$ nanoparticles were characterized by $\mathrm{XRD}$ in order to obtain information regarding crystallographic phases as well as the crystallite size. The obtained XRD diffractogram is shown in Figure 4. 


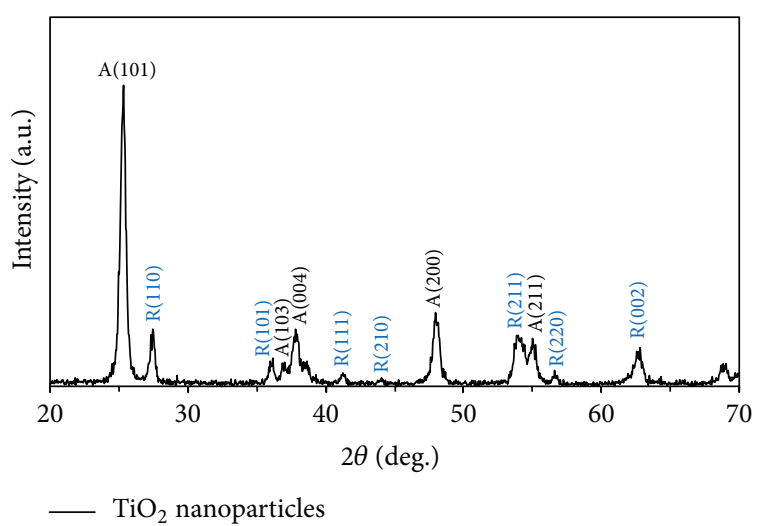

FIgURE 4: X-ray spectrum of $\mathrm{TiO}_{2}$ nanoparticles.

$\mathrm{X}$-ray diffractogram indicates that $\mathrm{TiO}_{2}$ nanoparticles comprise both anatase and rutile crystalline phases. The presence of an anatase crystalline phase was confirmed by

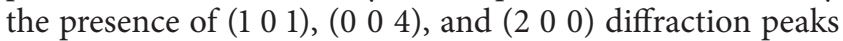
while the rutile crystalline phase presents (lllll), (1 1111$)$, and $\left(\begin{array}{lll}0 & 0 & 2\end{array}\right)$ diffraction peaks. Using the Scherrer equation (2) and taking the FWHM of $\left(\begin{array}{lll}1 & 0 & 1\end{array}\right)$ anatase and $\left(\begin{array}{lll}1 & 1 & 0\end{array}\right)$ rutile diffraction peaks, the crystallite sizes were determined. The mean crystallite grain size of the $\mathrm{TiO}_{2}$ nanoparticles was estimated to be in the range of $\sim 23 \mathrm{~nm}$ for anatase and $\sim 28 \mathrm{~nm}$ for the rutile phases. It was also observed that the anatase phase is present in much greater quantity of $82.4 \%$ than rutile, as calculated according the following equation:

$$
X_{A}=\left[1+1.26\left(\frac{I_{R}}{I_{A}}\right)\right]^{-1} \times 100,
$$

where $X_{A}$ is the weight fraction of the anatase phase in the samples and $I_{A}$ and $I_{R}$ correspond to the intensity of the most intense peaks of anatase (llll) and rutile (1 110$)$, respectively [20]. It has been reported that the photocatalytic activity depends on the crystalline phases present in the powders, the mixture of the two phases (anatase and rutile) being more effective regarding the photocatalytic activity [20,21].

3.2. Electrokinetic Behaviour of $\mathrm{TiO}_{2}$ Powder. To better understand the mechanisms related to photodegradation of Rh-B, it was necessary to study the surface properties of the substrates and the dye. An important issue to be considered refers to the solution $\mathrm{pH}$ value, which strongly influences the surface electric charge of the $\mathrm{TiO}_{2}$ nanoparticles in aqueous solution. Figure 5 shows the zeta potential $(\mathrm{ZP})$ as a function of $\mathrm{pH}$, which depends on the surface electrical charge of the $\mathrm{TiO}_{2}$ nanoparticles in aqueous solution $(20 \mathrm{~g} / \mathrm{L})$.

The isoelectric point (IEP) for a solution of $\mathrm{TiO}_{2}$ nanoparticles usually falls between $\mathrm{pH}$ values 6 and 7 (for $\sim 80 \%$ anatase $/ 20 \%$ rutile composition). For $\mathrm{pH}$ values below the IEP (acidic conditions), $\mathrm{TiO}_{2}$ becomes positively charged $\left(\mathrm{TiOH}_{2}{ }^{+}\right.$), while for $\mathrm{pH}$ values above the IEP (alkaline conditions), $\mathrm{TiO}_{2}$ becomes negatively charged $\left(\mathrm{TiO}^{-}\right)[10,16$, $17,19]$. However, the concentration of an aqueous dispersion strongly affects the measurement of ZP [22, 23]. In fact, the

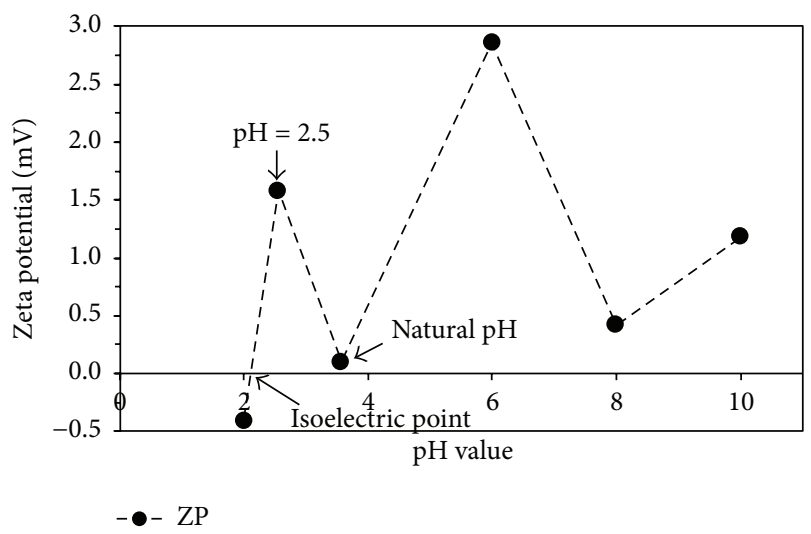

Figure 5: Zeta potential of $\mathrm{TiO}_{2}$ nanoparticles aqueous solution $(20 \mathrm{~g} / \mathrm{L})$ produced for functionalization of textile substrates.

nanoparticle solution used in this work is very concentrated $(20 \mathrm{~g} / \mathrm{L})$ and consequently the shape of the curve shown in Figure 5 is markedly different to a typical plot. Observing Figure 5, it appears that the $\mathrm{ZP}$ of nanoparticle is always positive for the range of $\mathrm{pH}$ investigated and IEP is obtained for $\mathrm{pH}$ of about 2 . Therefore, the stability of the solution is relatively weak, where $\mathrm{ZP}$ does not reach $30 \mathrm{mV}$, probably demonstrating the occurrence of phenomena related with nanoparticle aggregation. Generally, nanoparticle suspensions with zeta potential above $30 \mathrm{mV}$ (absolute value) are physically stable while below $5 \mathrm{mV}$ they undergo pronounced aggregation $[17,24]$.

As already stated, the adsorption of dyes is significantly influenced by $\mathrm{pH}$ and therefore the degradation rate of $\mathrm{Rh}-\mathrm{B}$ is modified. In this study, the solution of $\mathrm{TiO}_{2}$ nanoparticles was subjected to a change in $\mathrm{pH}$ in order to reach a value of 2.5.

The adsorption of the molecule on the electrode surface in this case can be enhanced by the interaction between negatively charged benzene ring and positively charged electrode surface. Electrostatic isopotential surface generated by MOPAC (Cache software) for rhodamine $\mathrm{B}$ is given in Figure 6. The electronegative part, which is distributed above the plane of the benzene ring, is well defined and separated from the electropositive one. This separated charge distribution may enhance a planar approach of the molecule to the electrode surface. The reaction can proceed towards hydroxylation of aromatic rings that leads to the degradation products. This suggestion is in agreement with the results of HPLC analysis, which indicate the presence of low molecular weight carboxylic acids among oxidation products.

3.3. Deposition of $\mathrm{TiO}_{2}$ Nanoparticles. In order to determine the amount of $\mathrm{TiO}_{2}$ material deposited on the textile substrates, the weight of different substrates in each step of the functionalization process was recorded. Table 1 shows the values for the initial and final weights. The difference between the final and initial weights, $\Delta M$, indicates the amount of nanoparticles deposited in the fibres of the textile substrates (adhesion). 
TABLE 1: Substrate's mass variation after deposition of $\mathrm{TiO}_{2}$ nanoparticles.

\begin{tabular}{|c|c|c|c|c|c|c|}
\hline \multirow{2}{*}{ Substrates } & \multicolumn{3}{|c|}{ Method 1} & \multicolumn{3}{|c|}{ Method 2} \\
\hline & $M_{\text {initial }}(\mathrm{g})$ & $M_{\text {final }}(\mathrm{g})$ & $\Delta M(\mathrm{~g})$ & $M_{\text {initial }}(\mathrm{g})$ & $M_{\text {final }}(\mathrm{g})$ & $\Delta M(\mathrm{~g})$ \\
\hline Cotton & 1,8276 & 1,9173 & 0,0897 & 1,7521 & 1,8440 & 0,0919 \\
\hline PLA & 2,0680 & 2,2771 & 0,2091 & 2,1307 & 2,1562 & 0,0255 \\
\hline Entretela & 1,5318 & 1,6353 & 0,1035 & 1,4917 & 1,6095 & 0,1178 \\
\hline
\end{tabular}

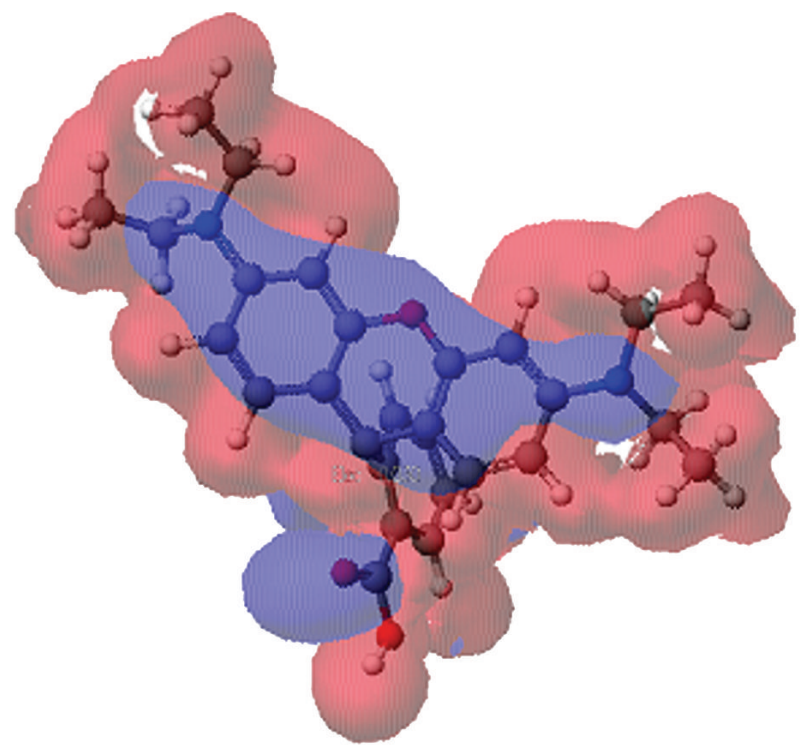

FIGURE 6: Electrostatic isopotential surface generated by MOPAC (Cache software) for rhodamine B. Blue: negative; red: positive electrostatic potential [19].

These results indicate that the Entretela is the textile with lower mass; however it is one of the substrates that have higher $\Delta M$. This can be understood because Entretela has a glue surface on one side. During the drying process this glue improves immobilization of $\mathrm{TiO}_{2}$ nanoparticles.

3.4. Morphology Analyses. The SEM analysis provides information on the morphology and dispersion of $\mathrm{TiO}_{2}$ nanoparticles on the textile substrate surface. In addition, Energy Dispersive X-Ray Spectroscopy (EDX) also provides a semiquantitative analysis of the chemical elements present on the substrates. The standard and functionalized substrates as well as after-washing ones are shown in Figure 7.

As can be seen, the standard (nonfunctionalized) substrates do not show any impurities between the fibres. After the functionalization process (by either method), $\mathrm{TiO}_{2}$ nanoparticles are viewed as being evenly distributed along all textile substrates but slightly agglomerated in Entretela. However, when the two functionalization methods are compared, the coating process appears to be more effective for Method 1, since the fibres are clearly covered with $\mathrm{TiO}_{2}$, confirming the $\Delta M$ values shown in Table 1 . A lesser amount of $\mathrm{TiO}_{2}$ material was found in the after-washing substrates in comparison with functionalized substrates. Thus, the five hot washes $\left(\approx 60^{\circ} \mathrm{C}\right)$ promoted the partial removal of $\mathrm{TiO}_{2}$ nanoparticles, leading to a concomitant decrease in the photocatalytic efficiency. However, there are still some $\mathrm{TiO}_{2}$ nanoparticles that remain strongly attached to the fibres evidencing their excellent stability even after the washing process. This behaviour suggests that the anchoring process of the $\mathrm{TiO}_{2}$ nanoparticles could involve the formation of chemical bonds via esterification of the surface hydroxyl ($\mathrm{OH})$ groups of the fibres with titanols (titanium sites linked to -OH groups) $[25,26]$.

The EDX spectra presented in Figure 8 show the presence of $\mathrm{TiO}_{2}$ nanoparticles and thus the effectiveness of the functionalization process. Other compounds present (carbon and oxygen) are characteristic of textile fibres (Figure 8).

3.5. Contact Angle Measurement. The wettability of a solid in water is dependent on the interfacial tension between the two surfaces (water/air, water/solid, and solid/air). If $\theta$ is approaching $0^{\circ}$ that indicates complete wetting of the surface and it is considered superhydrophilic; when it takes the value of $0^{\circ}<\theta<90^{\circ}$ the surface is considered hydrophilic; for angles among $90^{\circ}<\theta<120^{\circ}$ the surface is hydrophobic and a contact angle of $180^{\circ}$ has no surface wettability and is considered superhydrophobic. A surface with a lower contact angle of water exhibits better wettability with water compared to surfaces with higher contact angles. The surface tension is typical for every solid material or liquid as given in Table 2 [27].

Figure 9 shows the values of the contact angle for textile substrates.

The results suggest that the standard textile substrate with $100 \%$ cotton presents superhydrophilic behaviour, while the standard PLA and Entretela substrates demonstrate hydrophobic behaviour. This type of behaviour can be attributed to the nature of the fibres constituting the textile substrates since cotton is formed from natural fibres while PLA and Entretela consist of synthetic fibres (e.g., polyester) [28, 31]. With the functionalization using Method 1 , all tissues became superhydrophilic, which may indicate large adsorption of water $(5 \mu \mathrm{L})$ by the nanoparticles. After the photodegradation of the after-washing textile substrates (previously functionalized by Method 1), the 100\% cotton fabric demonstrated almost-hydrophobic behaviour $(\theta=$ $91.6^{\circ}$ ) due to the presence of residual surfactants from the cleaning process. In the case of PLA, this shows an intermediate behaviour between the standard sample (hydrophobic) and functionalized sample (hydrophilic) because cleaning promotes the removal of nanoparticles but does not completely eliminate them (previously established by SEM and absorbance). The high rate of removal of nanoparticles on 

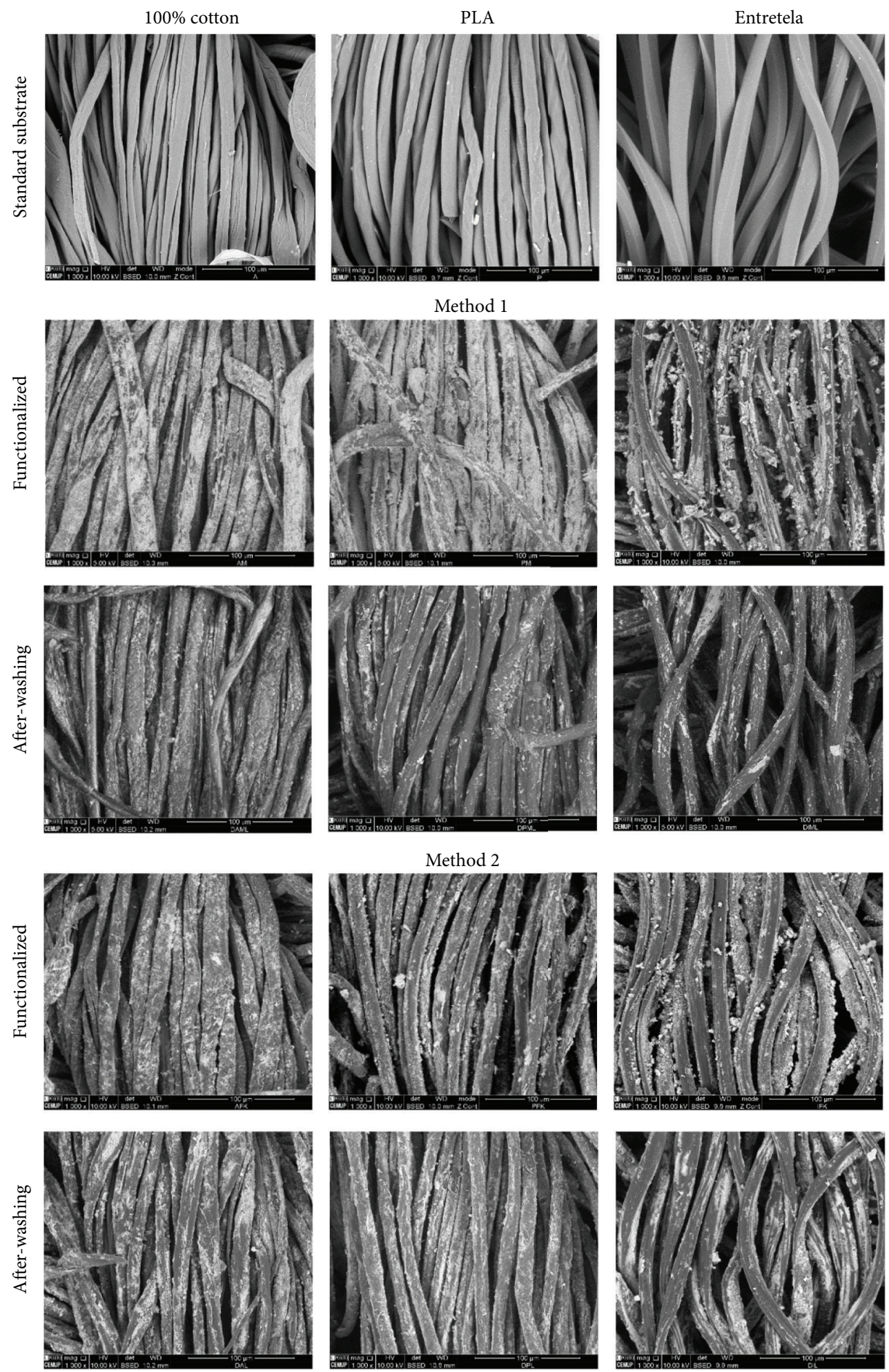

FIGURE 7: SEM micrographs of textile substrates (standard, functionalized, and functionalized after a washing process) prepared by Methods 1 and 2. Magnification: 1000x. 
TABLE 2: Critical surfaces tension and contact angles of water for polymers typically used for synthetic fibre production [27-30].

\begin{tabular}{|c|c|c|c|}
\hline Polymer surface & Abbreviation & Contact angle of water $\left(^{\circ}\right)$ & Surface tension $(\mathrm{mN} / \mathrm{m})$ \\
\hline Polytetrafluoroethylene & PTFE & 108 & 18,5 \\
\hline Polyvinyl fluoride & PVF & 80 & 28 \\
\hline Polyethylene & $\mathrm{PE}$ & 94 & 31 \\
\hline Polyvinyl chloride & PVC & 87 & 39 \\
\hline \multicolumn{4}{|c|}{ Common synthetic fibres } \\
\hline Polyester & PES & 81 & 43 \\
\hline Polyamide 66 & Nylon, PA & 70 & 46 \\
\hline Poly(lactic acid) & PLA & 124,3 & 36 \\
\hline \multicolumn{4}{|c|}{ Common natural fibres } \\
\hline Cotton & $\mathrm{CO}$ & 0 & 72 \\
\hline
\end{tabular}
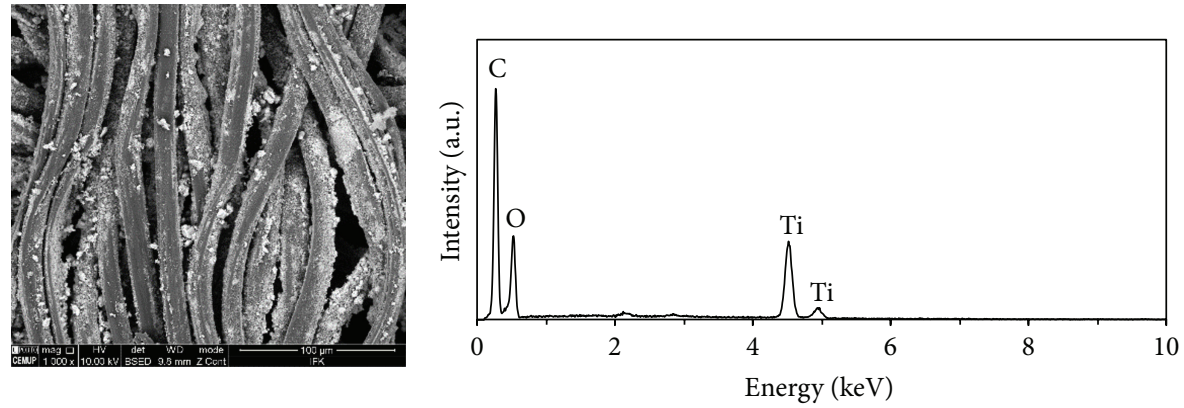

Figure 8: EDX spectra of a textile substrate functionalized with $\mathrm{TiO}_{2}$ nanoparticles (using Method 2).

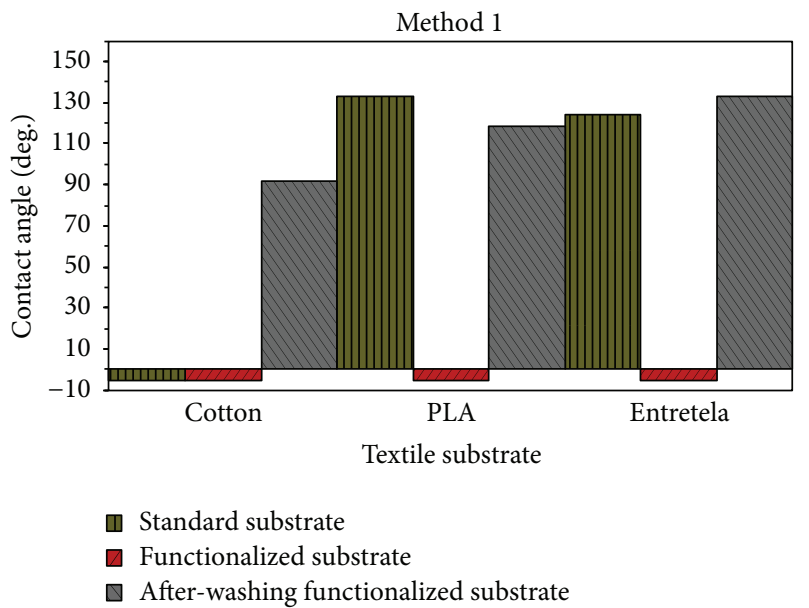

(a)

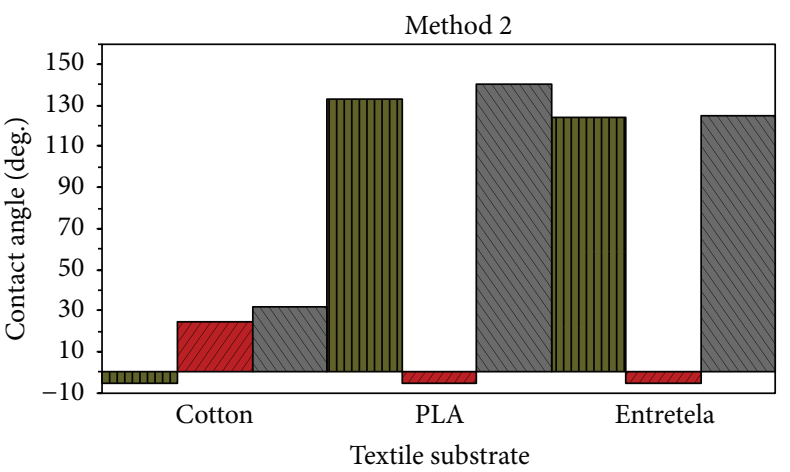

Standard substrate

Functionalized substrate

After-washing functionalized substrate

(b)

FIgURE 9: Description of the values of contact angle of the textile samples functionalized by (a) Method 1 and (b) Method 2.

Entretela after photodegradation, confirmed by SEM and absorbance spectroscopies, makes the surface hydrophobic, similar to standard substrate. The functionalization by Method 2 applied to $100 \%$ cotton fabric becomes slightly less superhydrophilic $\left(\theta=24.6^{\circ}\right) ; \mathrm{KOH}$ can attack the surface of this substrate (natural fibre). PLA and Entretela become superhydrophilic, suggesting the adsorption of water by the nanoparticles.

After washing textile substrates and photodegradation (functionalized by Method 2), there is an increase in the contact angle for cotton substrates, which may again indicate that the surfactant is present from the washing step. The PLA has an intermediate behaviour between the standard sample (hydrophobic) and the functionalized sample (hydrophilic), as noted earlier. The Entretela shows the behaviour as described above for Method 1.

3.6. Photocatalytic Activity. The photocatalytic activity of $\mathrm{TiO}_{2}$ photocatalyst (Aeroxide $\mathrm{TiO}_{2}$ P25) was evaluated in 


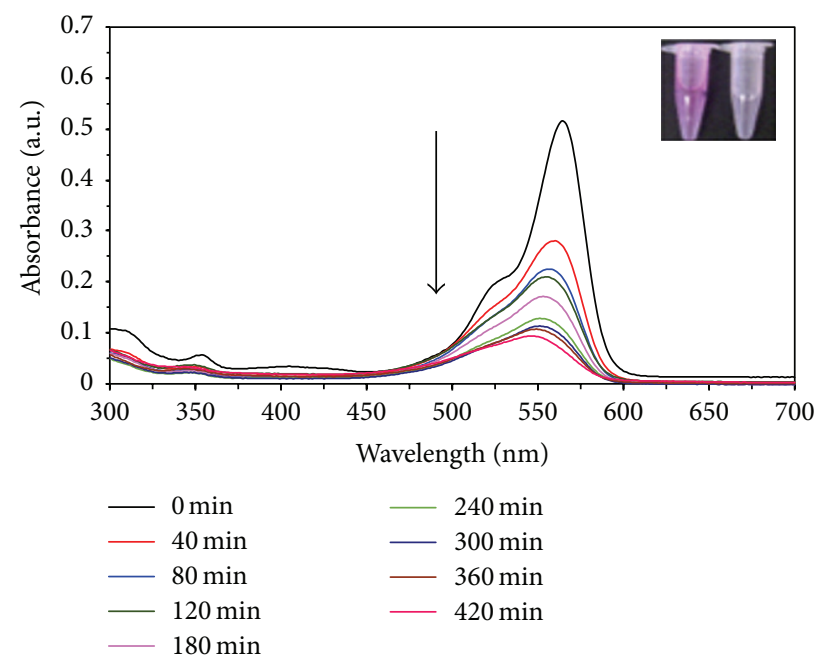

(a)

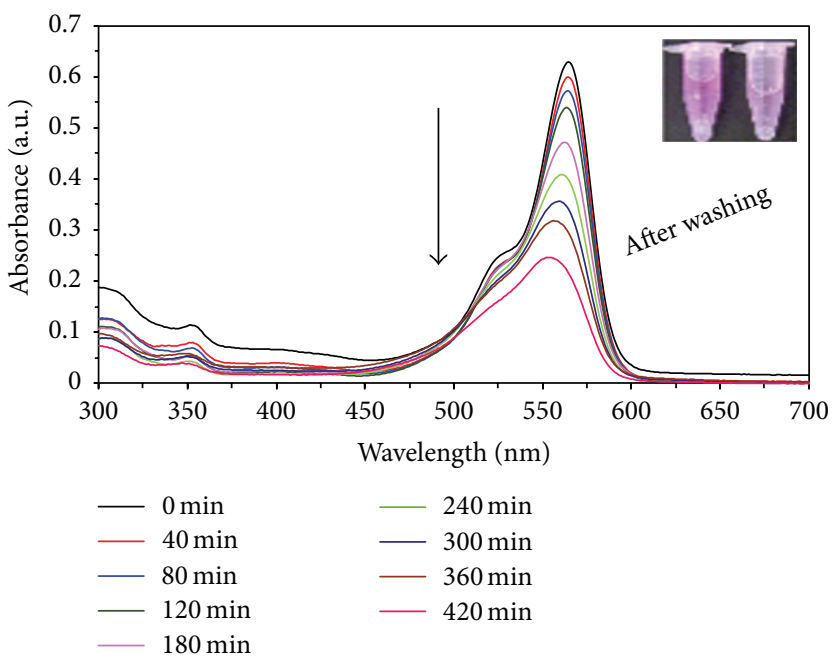

(b)

FIGURE 10: Absorption spectra of Rh-B aqueous solution in the presence of Entretela substrates prepared by Method 2 under dynamic regime. The data were acquired at different irradiation times and throughout $420 \mathrm{~min}$; (a) functionalized and (b) after-washing.

terms of degradation of Rh-B under visible light irradiation using UV-visible spectrophotometry.

Absorbance measurements were performed for all the produced samples. However, this work only presents the results for the Entretela substrates (after-washing) that were subjected to the dynamic regime. Figures $10(\mathrm{a})$ and $10(\mathrm{~b})$ show the absorption spectra of an Rh-B aqueous solution $(4 \mathrm{mg} / \mathrm{L})$ for different irradiation times, in the presence of $\mathrm{TiO}_{2}$ functionalized Entretela substrates and after-washing ones. The textile substrates were kept in the dark for several minutes while $\mathrm{Rh}-\mathrm{B}$ was being circulated in the dynamic system in order to consider adsorption of dye in the substrate.

As shown in Figure 10, the maximum Rh-B absorption peak, at around $564 \mathrm{~nm}$, gradually decreases during light irradiation. The decrease of the absorption peak indicates that the photodegradation process is taking place.

Under a dynamic regime, the decrease of the absorption peak is much more evident for the functionalized substrates, when compared with after-washing substrates, due to partial removal of $\mathrm{TiO}_{2}$ nanoparticles. Besides this decrease, the maximum absorbance peak is shifted to $544 \mathrm{~nm}$ and $552 \mathrm{~nm}$ (Figures 10(a) and 10(b), resp.), suggesting the generation of intermediates or new products.

These shifts, known as hypsochromic shifts (or blue shifts), are a result of two photodegradation pathways for Rh-B: (A) cleavage of the whole conjugated chromophore structure and (B) stepwise formation of a series of $\mathrm{N}$ deethylation intermediates [32,33]. The absorbance gradually decreases presenting a blue shift for both spectra, $20 \mathrm{~nm}$ (Figure 10(a)) and $12 \mathrm{~nm}$ (Figure 10(b)), suggesting that the cleavage of the whole conjugated chromophore structure is the main pathway [32]. However, in most cases, the two degradation pathways coexist and compete [32]. The cleavage of the conjugated chromophore structure can be estimated by the peak intensity. Accordingly, for functionalized and after-washing substrates about $81.8 \%$ and $60.8 \%$, respectively, are destroyed within the $420 \mathrm{~min}$ of light irradiation. The hypsochromic shift can be also related to quantum size effects, typical of nanoparticles, which present a higher band gap [26, 32].

In addition, the $\mathrm{TiO}_{2}$ nanoparticles (P25) used for the functionalization process have a higher crystallinity (Figure 4) that leads to a quicker cleavage of conjugated chromophore structure and a slower $\mathrm{N}$-deethylation process. The proposed pathways for degradation mechanism of light irradiated Rh-B dye are shown in Figure 15.

The absorbance spectra of Rh-B aqueous solution dye enable the evaluation of the photocatalytic efficiency, $\eta$, over time. The rate of Rh-B consumed in a chemical reaction can be written as

$$
-\frac{d C}{d t}=k C^{n}
$$

where $C$ is the concentration of the Rh-B aqueous solution, $n$ is the kinetic order of the chemical reaction, and $k$ is the rate constant of the photodegradation process. At low concentrations and for a specific instant of time, the absorbance of the solution, $A_{t}$, is related to its solution's concentration through the Beer-Lambert law; that is, $A_{t}=\varepsilon l C_{t}$, where $\varepsilon$ is the molar extinction coefficient, $l$ is the light path length, and $C_{t}$ is the solution concentration.

For a reaction that follows first-order kinetics, the photodegradation efficiency, $\eta$, of Rh-B can be calculated according to the following equation [20]:

$$
\eta(\%)=\left[1-\left(\frac{A_{t}}{A_{0}}\right)\right] \times 100,
$$

where $A_{0}$ is the absorbance at zero time [20]. Therefore, the change of Rh-B concentration can be evaluated by measuring the change in the intensity of its main absorption peak.

Using the absorption spectra of the produced samples, it was possible to calculate the corresponding photodegradation efficiencies $(\eta)$ by applying (4). Figure 11 compares 


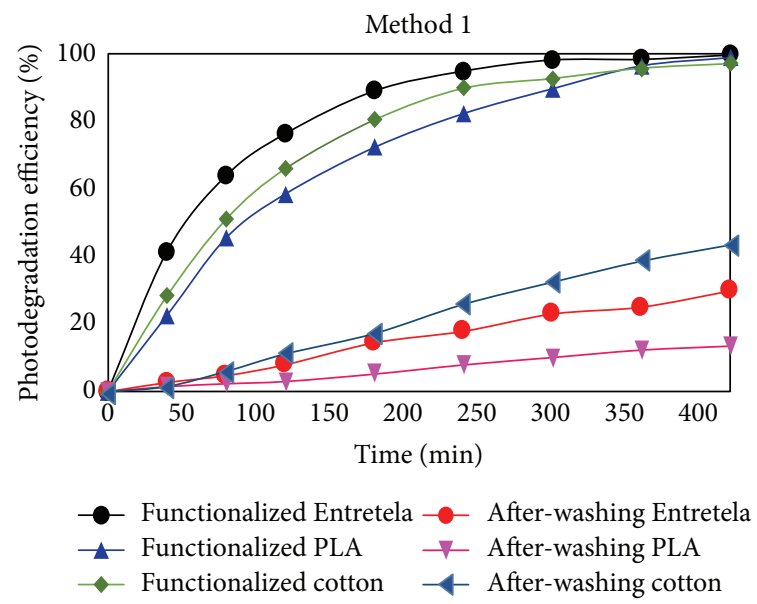

(a)

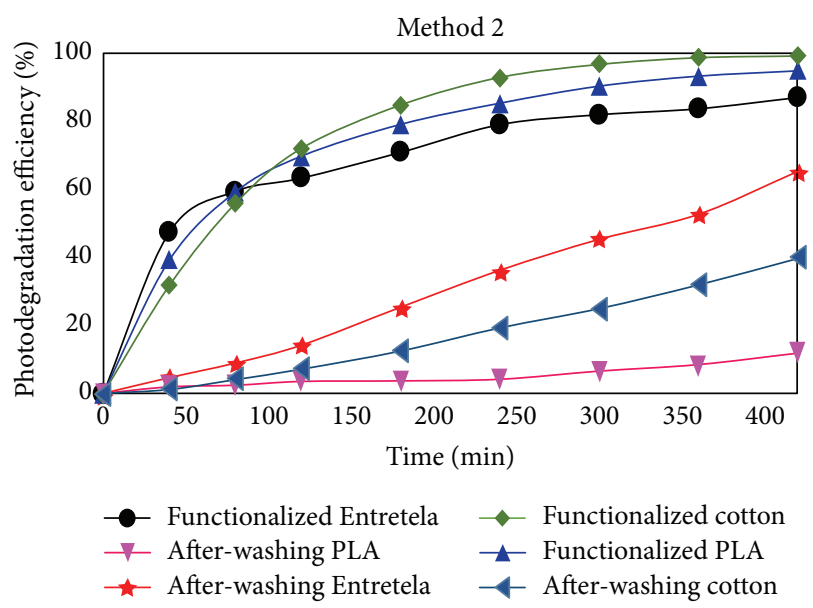

(b)

FIGURE 11: Photodegradation efficiency of all functionalized and after-washing textile substrates: (a) Method 1 and (b) Method 2.

the photocatalytic efficiencies of all functionalized substrates using Methods 1 and 2.

It can be observed that all the textile substrates show a similar behaviour. For the functionalized substrates, the photocatalytic efficiency is higher than the after-washing ones. In fact, this behaviour was already predictable since it was expected that a number of $\mathrm{TiO}_{2}$ nanoparticles could have been pulled from the surface of textile substrates due to some adhesion problems. Regarding the functionalized substrates, it is possible to verify that they exhibit the highest photodegradation efficiencies (higher than 85\% at around $240 \mathrm{~min}$ ) for Rh-B degradation under light irradiation. Moreover, the functionalized textile substrates that were subjected to the washing process, despite exhibiting a decrease of their photodegradation efficiencies, still present quite reasonable photodegradation efficiency since the corresponding values can still be higher than $65 \%$, as is the case of Entretela substrate, which was functionalized via Method 2. However, the photodegradation efficiency of PLA substrate under the same conditions was only $11 \%$.

By using the UV-Vis spectroscopy data from the produced samples, it is possible to determine the photodegradation rate constant, $k$, of $\mathrm{Rh}-\mathrm{B}$ dye. Assuming pseudo-first-order reaction kinetics and performing the integration of (4), a plot of $\ln \left(C_{t} / C_{0}\right)$ as a function of irradiation time can be drawn. It is noted that $C_{0}$ is the solution concentration at zero time, which is directly related with the solution's absorbance at the same instant, $A_{0}$, through the Beer-Lambert law.

Figure 12 shows the plot of $\ln \left(C_{t} / C_{0}\right)$ against irradiation time for functionalized Entretela substrates before and after being subjected to the washing process.

As can be observed, the plotted data show an almost linear behaviour. In this way, the photodegradation rate constants $k$ can be obtained from the slopes of the fitting lines. The calculated $k$ values correspond to $k_{1}=2.4 \times 10^{-3} \mathrm{~min}^{-1}$ and $k_{2}=4.2 \times 10^{-3} \mathrm{~min}^{-1}$ for functionalized and after-washing Entretela textile substrates, respectively.

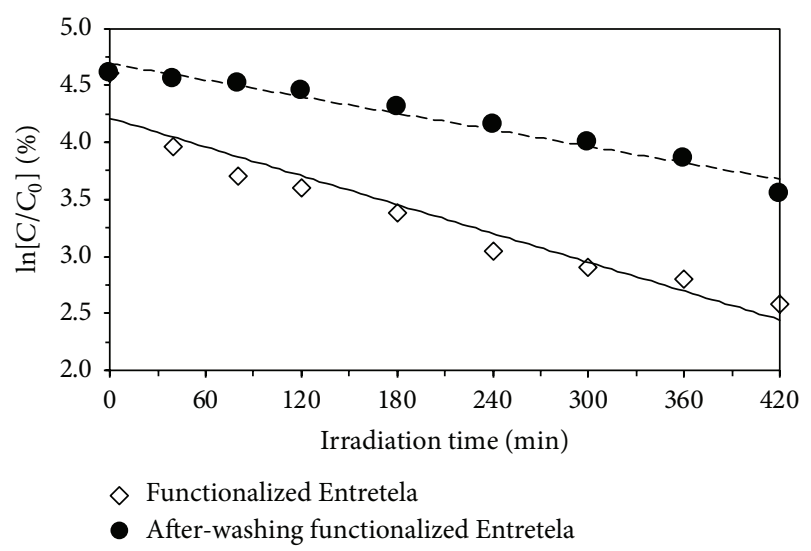

FIGURE 12: Photodegradation of $\mathrm{Rh}-\mathrm{B}$ promoted by $\mathrm{TiO}_{2}$ functionalized Entretela substrates after-washing prepared by Method 2 under the dynamic regime.

The plot shows that the photocatalytic degradation efficiency is higher in the functionalized Entretela, than those after washing [32], due to the reduced density of nanoparticles, which is understood given the aggressiveness of the laundering process, and the surface adhesion of the $\mathrm{TiO}_{2}$ nanoparticles can be reduced.

3.7. Chromatographic Analysis. The photooxidation reaction was monitored as a function of time by HPLC, where the substrate and reaction products were separated using C18 analytical column. Analyses of the reaction products during the photooxidation process would help to better comprehend the details of the reaction process $[10,34]$. The target substrate $\mathrm{Rh}-\mathrm{B}$, which contains four $\mathrm{N}$-ethyl groups at either side of the xanthene ring (Figure 6), is relatively stable in the aqueous solution upon visible light irradiation $[32,33]$.

The consumption of Rh-B during the photodegradation process was determined using a calibration curve constituted 


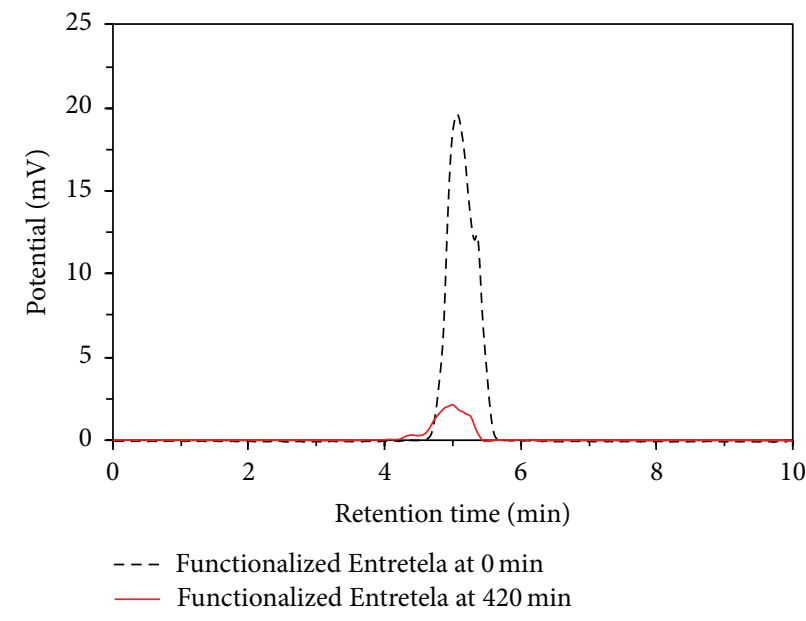

(a)

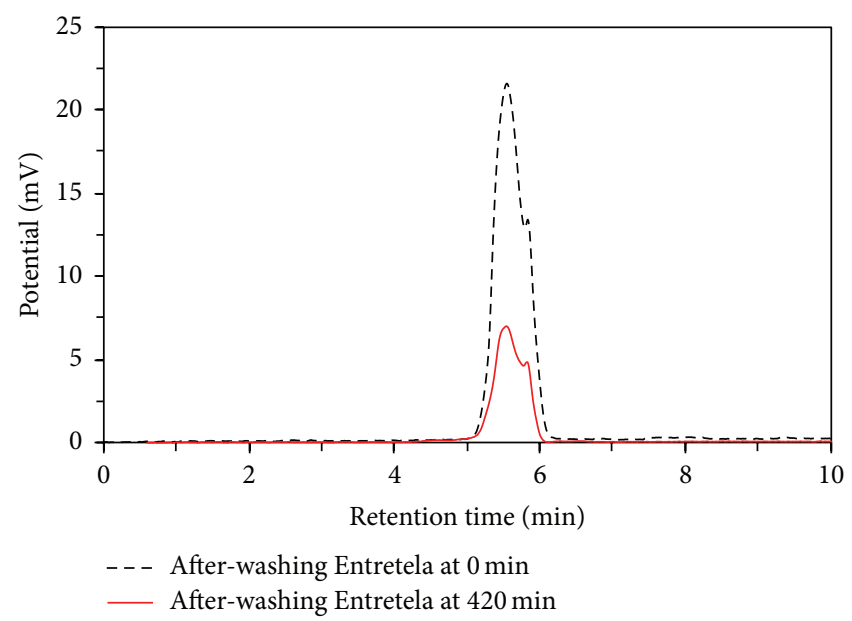

(b)

FIGURE 13: HPLC chromatograms of Rh-B recorded at $564 \mathrm{~nm}$, at $0 \mathrm{~min}$ and $420 \mathrm{~min}$ of photodegradation for (a) functionalized Entretela and (b) after-washing, functionalized by Method 2 .

by seven concentration levels of the compounds in the range between initial concentration and lowest expectable concentration. Recorded typical HPLC chromatograms are shown in Figure 13.

As observed for the Rh-B chromatograms of Figure 13, a major peak with retention time, $t_{R}$, of $5.07 \mathrm{~min}$ was detected. For functionalized Entretela, a final area corresponding to $17.5 \%$ of the initial area at the end of the treatment after 420 min of reaction was observed. In case of after-washing Entretela, the decrease of the concentration corresponds to the $50 \%$ of the initial value. These concentrations ratios correlate with optical absorbance ratios for the same time gap.

Furthermore, final concentrations calculated at the end of the reaction confirm the degradation of $\mathrm{Rh}-\mathrm{B}$, once the initial value ( $4 \mathrm{ppm}$ ) has decreased to $0.7 \mathrm{ppm}$ and $2 \mathrm{ppm}$, in functionalized and after-washing Entretela, respectively.

Figure 14 shows the GC-MS analysis of the trimethylsilylated reaction products. The following degradation products were determined at the end of the reaction using NIST 08 Mass Spectral Library: oxalic acid $\left(t_{R}=6.69 \mathrm{~min}\right), 2$ hydroxypropanoic acid $\left(t_{R}=6.44 \mathrm{~min}\right)$, 3-hydroxybutanoic acid $\left(t_{R}=8.30 \mathrm{~min}\right), 4$-ketopentanoic acid $\left(t_{R}=7.70 \mathrm{~min}\right)$, butanedioic acid $\left(t_{R}=11.20 \mathrm{~min}\right)$, benzoic acid $\left(t_{R}=\right.$ $9.83 \mathrm{~min})$, and benzene dicarboxylic acid $\left(t_{R}=19.24 \mathrm{~min}\right)$. The presence of these compounds in the reaction mixture was also confirmed by HPLC-ESI(+)-MS from the corresponding $(\mathrm{M}+\mathrm{H})^{+}$ions. The presence of di- and trihydroxybenzoic acids among the reaction products was also determined by this technique from $\mathrm{m} / \mathrm{z}$ ratios of, respectively, 155 and 171 $[32,34,35]$.

According to pathways illustrated below (Figure 14), the formation of these compounds corresponds to the last stage of the degradation processes, demonstrating the efficient degradation of the dye in this case. Further degradation of oxalic acid may produce the innocuous compounds, as carbon dioxide and water, through intramolecular dehydration (Figure 16).

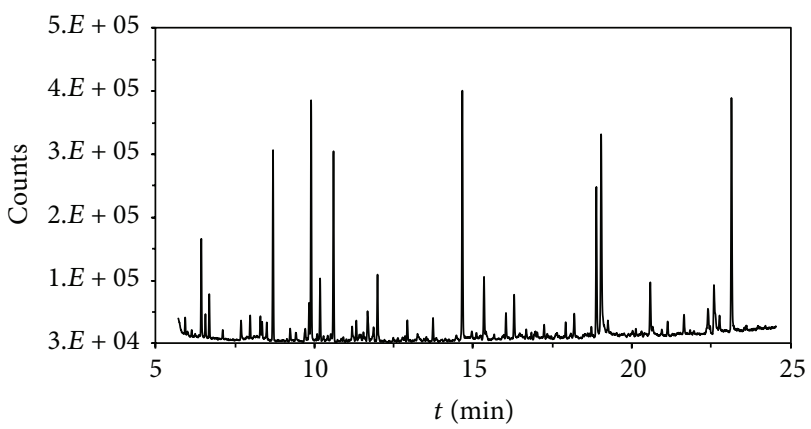

FIGURE 14: GC-MS chromatogram of the trimethylsilylated derivatives from the degradation products of rhodamine $\mathrm{B}$.

3.8. Electrical Energy Determination. Since photocatalysis of aqueous organic pollutants is an electric energy intensive process and electric energy can represent a major fraction of the operating costs, simple figures-of-merit based on electric energy consumption can be very useful and informative. Recently, the Photochemistry Commission of the International Union of Pure and Applied Chemistry (IUPAC) proposed two figures-of-merit for advanced oxidation processes (AOP) on the use of electrical energy [7].

In the case of low pollutant concentrations the appropriate figure-of-merit is the electrical energy per order $\left(E_{\mathrm{EO}}\right)$, defined as the number of $\mathrm{kWh}$ of electrical energy required to reduce the concentration of a pollutant by one order of magnitude (90\%) in $1 \mathrm{~m}^{3}$ of contaminated water. The energy required for achieving the chosen level of abatement, for a fixed volume of wastewater, can be thus calculated trough the following equation [37]:

$$
\begin{aligned}
E_{\mathrm{EO}} & =\frac{P \times t \times 1000}{V_{0} \times 60 \times \log \left(C_{i} / C_{f}\right)}, \\
E_{\mathrm{EO}} & =\frac{38.4 \times P}{V_{0} \times K},
\end{aligned}
$$




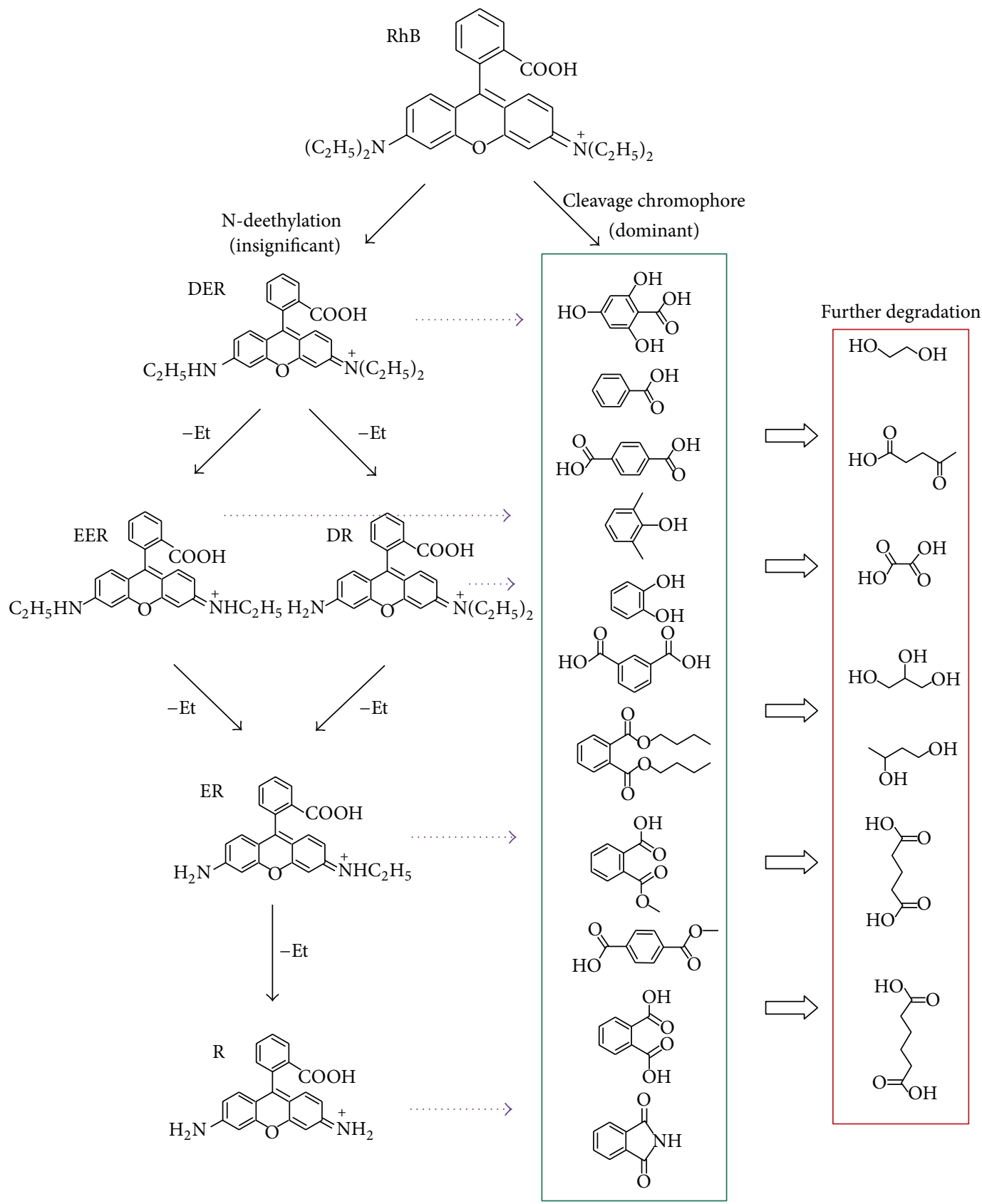

FIgURE 15: Proposed pathway of Rh-B irradiated [32, 34].

where $P$ is the lamp power $(\mathrm{kW}), k$ the pseudo-first-order constant $\left(\mathrm{min}^{-1}\right), V_{0}$ the volume of the tested solution $(L)$, and $E_{\mathrm{EO}}$ the energy required $\left(\mathrm{kWh} / \mathrm{m}^{3}\right)$. Values not higher than $2.5 \mathrm{kWh} / \mathrm{m}^{3}$ are considered suitable for practical application [37-39].

The electric energy $\left(\mathrm{kWh} / \mathrm{m}^{3}\right)$ required to result in decolourization of $4 \mathrm{mg} / \mathrm{L}$ of the dye from $400 \mathrm{~mL}$ dye solution, along with the resulting costs, is given in Table 3.

Few data are reported in the literature for AOP overall costs and due to their dependence on the effluent and plant characteristics their direct comparison is (often) meaningless [37]. According to the threshold value, for the system being considered suitable for practical application, our system has a much smaller value and it is possible to consider it suitable for industrial applications. Additionally there will be small cost factors for the photocatalyst used and for visible light lamp replacement [7].

\section{Conclusions}

In this work, the textile substrates were functionalized with $\mathrm{TiO}_{2}$ nanoparticles by padding. The study shows that the concentration of the $\mathrm{TiO}_{2}$ nanoparticle solution significantly affects the behaviour of $\mathrm{ZP}$, and the IEP is found for $\mathrm{pH}$ of $\sim 2$. 
TABLE 3: The pseudo-first-order rate constant $(k), E_{\mathrm{EO}}$ values, and the contribution to treatment cost from electrical energy for photocatalysis of the functionalized and after-washing Entretela.

\begin{tabular}{lccc}
\hline & \multicolumn{2}{c}{ Dynamic regime } & Treatment cost $\left.(€ / \mathrm{kWhm})^{-3}\right)[40]$ \\
\hline Substrate & $k\left(\mathrm{~min}^{-1}\right)$ & $E_{\mathrm{EO}}\left(\mathrm{kWh} / \mathrm{m}^{3}\right)$ & 1.80 \\
After-washing Entretela & $2.4 \times 10^{-3}$ & 13.13 & 3.14 \\
\hline
\end{tabular}

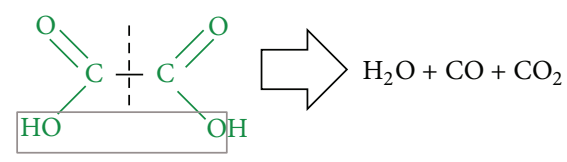

FIGURE 16: Reaction of innocuous compounds formation by dehydration of oxalic acid molecule [36].

$\mathrm{ZP}$ remained positive for the used concentration, suggesting that it is an index to be considered in applications, where surfaces with negative charge are used. Of the two different methods of functionalization used, Method 1 focused on an aqueous solution with a wetting compound, resulting in a higher deposited mass than Method 2, which used a $\mathrm{KOH}$ solution to activate $\mathrm{OH}^{-}$groups on the surface of textile substrates. The highest photocatalytic efficiency of $65 \%$ was observed for Entretela while the lowest was 11\% for PLA after washing. Chromatographic analyses confirm a product of the $\mathrm{Rh}-\mathrm{B}$ photodegradation process to be oxalic acid. It can be concluded that the methods of fixation of nanoparticles and the textile substrates used have a high potential for degradation of dyes. In actual context, textile substrates will always be subjected to cyclic action of wear, promoted by the passage of effluents, but show promise in industrial applications, for example, in effluent conduits (those that show high photodegradation in dynamic regime) and in air purification systems (those that show better nanoparticle adhesion).

\section{Conflict of Interests}

The authors declare that there is no conflict of interests regarding the publication of this paper.

\section{Acknowledgments}

The authors would like to acknowledge FCT-Fundação para a Ciência e Tecnologia-for funding under the Project PTDC/FIS/120412/2010, "NanoEcoBuild: Nanobased Concepts for Innovative \& Ecosustainable Constructive Material's Surfaces," and the European Commission through FP7PEOPLE-2010-IRSES-NanoCIS (269279) project.

\section{References}

[1] A. Kunz, P. Peralta-Zamora, S. G. De Moraes, and N. Durán, "New tendencies on textile effluent treatment," Quimica Nova, vol. 25 , no. 1 , pp. 78-82, 2002.
[2] M. C. Silva, A. D. Corrêa, J. A. Torres, and M. T. Amorim, "Descoloração de corantes industriais e efluentes têxteis simulados por peroxidase de nabo (Brassica campestre)," Química Nova, vol. 35, no. 5, pp. 889-894, 2012.

[3] R. M. Christie, Environmental Aspects of Textile Dyeing, Woodhead Publishing Series in Textiles, Woodhead Publishing, Cambridge, UK, 2007.

[4] D. Li, H. Zheng, Q. Wang et al., "A novel double-cylindricalshell photoreactor immobilized with monolayer $\mathrm{TiO}_{2}$-coated silica gel beads for photocatalytic degradation of Rhodamine $\mathrm{B}$ and Methyl Orange in aqueous solution," Separation and Purification Technology, vol. 123, pp. 130-138, 2014.

[5] S. H. Jeong, R. Gulbinas, R. K. Jain, and J. E. Taylor, "The impact of combined water and energy consumption eco-feedback on conservation," Energy and Buildings, vol. 80, pp. 114-119, 2014.

[6] T. S. Natarajan, M. Thomas, K. Natarajan, H. C. Bajaj, and R. J. Tayade, "Study on UV-LED/ $/ \mathrm{TiO}_{2}$ process for degradation of Rhodamine B dye," Chemical Engineering Journal, vol. 169, no. 1-3, pp. 126-134, 2011.

[7] A. R. Khataee, M. N. Pons, and O. Zahraa, "Photocatalytic degradation of three azo dyes using immobilized $\mathrm{TiO}_{2}$ nanoparticles on glass plates activated by UV light irradiation: Influence of dye molecular structure," Journal of Hazardous Materials, vol. 168, no. 1, pp. 451-457, 2009.

[8] R. M. Dallago, A. Smaniotto, and L. C. A. de Oliveira, "Solid waste from tanneries as adsorbent for the removal of dyes in aqueous medium," Quimica Nova, vol. 28, no. 3, pp. 433-437, 2005.

[9] F. Harrelkas, A. Paulo, M. M. Alves et al., "Photocatalytic and combined anaerobic-photocatalytic treatment of textile dyes," Chemosphere, vol. 72, no. 11, pp. 1816-1822, 2008.

[10] L. Pereira, R. Pereira, C. S. Oliveira et al., "UV/TiO 2 photocatalytic degradation of xanthene dyes," Photochemistry and Photobiology, vol. 89, no. 1, pp. 33-39, 2013.

[11] M. F. Abdel-Messih, M. A. Ahmed, and A. S. El-Sayed, "Photocatalytic decolorization of Rhodamine $\mathrm{B}$ dye using novel mesoporous $\mathrm{SnO}_{2}-\mathrm{TiO}_{2}$ nano mixed oxides prepared by solgel method," Journal of Photochemistry and Photobiology A: Chemistry, vol. 260, pp. 1-8, 2013.

[12] R. Thapa, S. Maiti, T. H. Rana, U. N. Maiti, and K. K. Chattopadhyay, "Anatase $\mathrm{TiO}_{2}$ nanoparticles synthesis via simple hydrothermal route: degradation of orange II, Methyl Orange and Rhodamine B," Journal of Molecular Catalysis A: Chemical, vol. 363-364, pp. 223-229, 2012.

[13] P. Wilhelm and D. Stephan, "Photodegradation of rhodamine $\mathrm{B}$ in aqueous solution via $\mathrm{SiO}_{2} @ \mathrm{TiO}_{2}$ nano-spheres," Journal of Photochemistry and Photobiology A: Chemistry, vol. 185, no. 1, pp. 19-25, 2007.

[14] J. O. Carneiro, V. Teixeira, P. Carvalho, S. Azevedo, and N. Manninen, "Self-cleaning smart nanocoatings," Nanocoatings 
and Ultra-Thin Films: Technologies and Applications, pp. 397413, 2011.

[15] Y. Lin, Z. Jiang, C. Zhu et al., "Electronic and optical performances of $\mathrm{Si}$ and $\mathrm{Fe}$-codoped $\mathrm{TiO}_{2}$ nanoparticles: a photocatalyst for the degradation of methylene blue," Applied Catalysis B: Environmental, vol. 142-143, pp. 38-44, 2013.

[16] P. Wilhelm and D. Stephan, "On-line tracking of the coating of nanoscaled silica with titania nanoparticles via zeta-potential measurements," Journal of Colloid and Interface Science, vol. 293, no. 1, pp. 88-92, 2006.

[17] J. O. Carneiro, S. Azevedo, V. Teixeira et al., "Development of photocatalytic asphalt mixtures by the deposition and volumetric incorporation of $\mathrm{TiO}_{2}$ nanoparticles," Construction and Building Materials, vol. 38, pp. 594-601, 2013.

[18] T. Watanabe, A. Nakajima, R. Wang et al., "Photocatalytic activity and photoinduced hydrophilicity of titanium dioxide coated glass," Thin Solid Films, vol. 351, no. 1-2, pp. 260-263, 1999.

[19] F. Chen, J. Zhao, and H. Hidaka, "Highly selective deethylation of Rhodamine $\mathrm{B}$ : adsorption and photooxidation pathways of the dye on the $\mathrm{TiO}_{2} / \mathrm{SiO}_{2}$ composite photocatalyst," International Journal of Photoenergy, vol. 5, no. 4, pp. 209-217, 2003.

[20] J. O. Carneiro, S. Azevedo, F. Fernandes et al., "Synthesis of irondoped $\mathrm{TiO}_{2}$ nanoparticles by ball-milling process: the influence of process parameters on the structural, optical, magnetic, and photocatalytic properties," Journal of Materials Science, vol. 49, no. 21, pp. 7476-7488, 2014.

[21] O. Carp, C. L. Huisman, and A. Reller, "Photoinduced reactivity of titanium dioxide," Progress in Solid State Chemistry, vol. 32, no. 1-2, pp. 33-177, 2004.

[22] M. E. Labib and R. Williams, "The use of zeta-potential measurements in organic solvents to determine the donoracceptor properties of solid surfaces," Journal of Colloid and Interface Science, vol. 97, no. 2, pp. 356-366, 1984.

[23] M. Kaszuba, J. Corbett, F. M. Watson, and A. Jones, "High-concentration zeta potential measurements using light-scattering techniques," Philosophical Transactions a: Mathematical, Physical and Engineering Sciences, vol. 368, no. 1927, pp. 4439-4451, 1927.

[24] D. L. Liao, G. S. Wu, and B. Q. Liao, "Zeta potential of shapecontrolled $\mathrm{TiO}_{2}$ nanoparticles with surfactants," Colloids and Surfaces A: Physicochemical and Engineering Aspects, vol. 348, no. 1-3, pp. 270-275, 2009.

[25] E. Gianotti, V. Dellarocca, M. L. Peña et al., "Unequivocal evidence of the presence of titanols in Ti-MCM-48 mesoporous materials. A combined diffuse reflectance UV-Vis-Nir and 29SiMAS-NMR study," Research on Chemical Intermediates, vol. 30, no. 9, pp. 871-877, 2004.

[26] M. J. Uddin, F. Cesano, D. Scarano et al., "Cotton textile fibres coated by $\mathrm{Au} / \mathrm{TiO}_{2}$ films: synthesis, characterization and self cleaning properties," Journal of Photochemistry and Photobiology A: Chemistry, vol. 199, no. 1, pp. 64-72, 2008.

[27] R. Paul, Functional Finishes for Textiles: Improving Comfort, Performance and Protection, Handbook of Elsevier, Woodhead Publishing, Cambridge, UK, 2015.

[28] N. D. Tissera, R. N. Wijesena, J. R. Perera, K. M. N. de Silva, and G. A. J. Amaratunge, "Hydrophobic cotton textile surfaces using an amphiphilic graphene oxide (GO) coating," Applied Surface Science, vol. 324, pp. 455-463, 2015.

[29] Q. Wei, Surface Modification of Textiles, Woodhead Publishing, Cambridge, UK, 2009.
[30] L. Zirkel, "PLA for thermoforming," Bioplastics Magazine, vol. 7, pp. 18-20, 2004.

[31] M. Zhang, S. Wang, C. Wang, and J. Li, "A facile method to fabricate superhydrophobic cotton fabrics," Applied Surface Science, vol. 261, pp. 561-566, 2012.

[32] Y. Fan, G. Chen, D. Li et al., "Highly selective deethylation of Rhodamine $\mathrm{B}$ on $\mathrm{TiO}_{2}$ prepared in supercritical fluids," International Journal of Photoenergy, vol. 2012, Article ID 173865, 7 pages, 2012.

[33] C. Chen, W. Zhao, P. Lei, J. Zhao, and N. Serpone, "Photosensitized degradation of dyes in polyoxometalate solutions versus $\mathrm{TiO}_{2}$ dispersions under visible-light irradiation: mechanistic implications," Chemistry -A European Journal, vol. 10, no. 8, pp. 1956-1965, 2004.

[34] K. Yu, S. Yang, H. He, C. Sun, C. Gu, and Y. Ju, "Visible light-driven photocatalytic degradation of rhodamine $\mathrm{B}$ over $\mathrm{NaBiO}_{3}$ : pathways and mechanism," Journal of Physical Chemistry A, vol. 113, no. 37, pp. 10024-10032, 2009.

[35] X. Hu, T. Mohamood, W. Ma, C. Chen, and J. Zhao, "Oxidative decomposition of rhodamine $\mathrm{B}$ dye in the presence of $\mathrm{VO}_{2}{ }^{+}$ and/or Pt(IV) under visible light irradiation: $\mathrm{N}$-deethylation, chromophore cleavage, and mineralization," The Journal of Physical Chemistry B, vol. 110, no. 51, pp. 26012-26018, 2006.

[36] K. S. Kim and M. A. Barteau, "Structure and composition requirements for deoxygenation, dehydration, and ketonization reactions of carboxylic acids on $\mathrm{TiO}_{2}(001)$ single-crystal surfaces," Journal of Catalysis, vol. 125, no. 2, pp. 353-375, 1990.

[37] R. Andreozzi, V. Caprio, A. Insola, and R. Marotta, "Advanced oxidation processes (AOP) for water purification and recovery," Catalysis Today, vol. 53, no. 1, pp. 51-59, 1999.

[38] S. R. Cater, M. I. Stefan, J. R. Bolton, and A. SafarzadehAmiri, "UV/ $\mathrm{H}_{2} \mathrm{O}_{2}$ treatment of methyl tert-butyl ether in contaminated waters," Environmental Science and Technology, vol. 34, no. 4, pp. 659-662, 2000.

[39] J. R. Bolton and S. R. Cater, "Homogeneous photodegradation of pollutants in contaminated water: an introduction," in Aquatic and Surface Photochemistry, G. R. Helz, R. G. Zeep, and D. G. Crosby, Eds., chapter 33, pp. 467-490, Lewis Publishers, Boca Raton, Fla, USA, 1994.

[40] Energia EDP, 2015, https://energia.edp.pt/particulares/energia/ tarifarios-2015.aspx. 

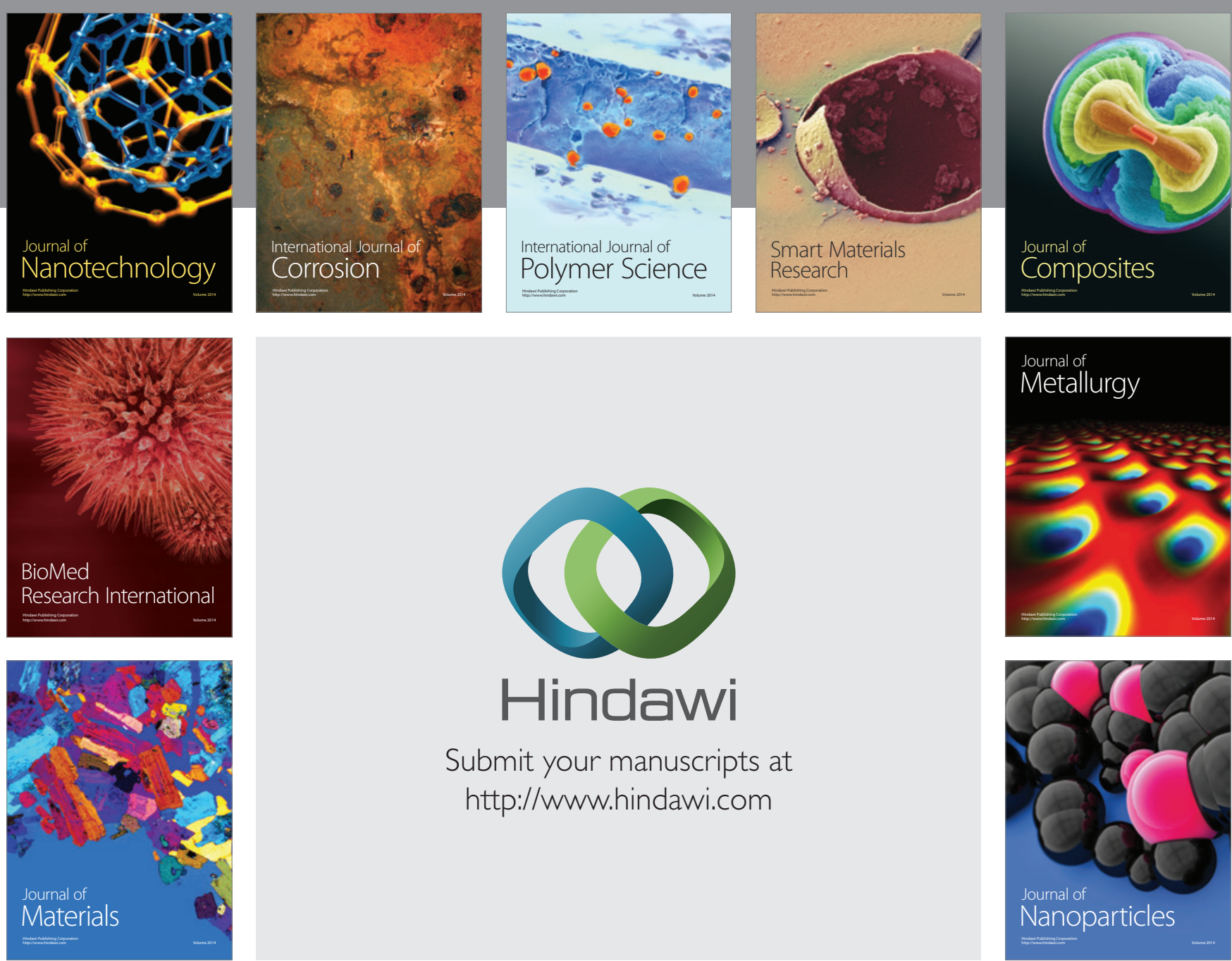

\section{Hindawi}

Submit your manuscripts at

http://www.hindawi.com

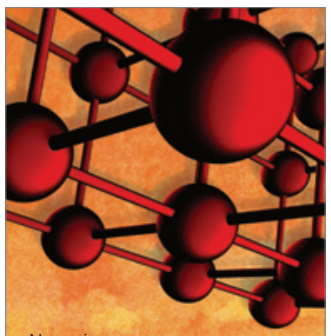

Materials Science and Engineering
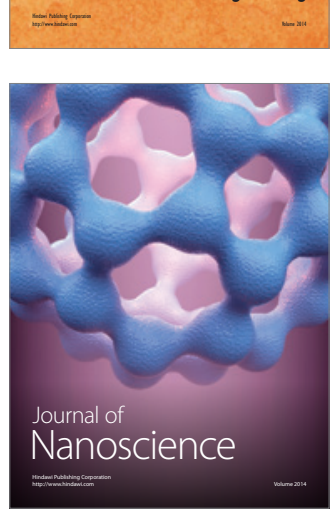
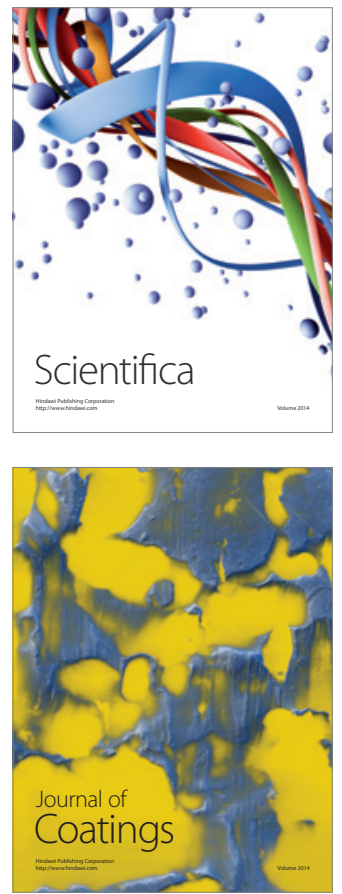
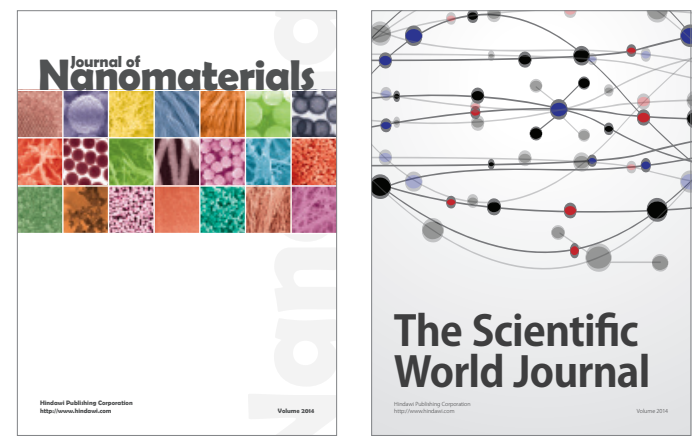

The Scientific World Journal
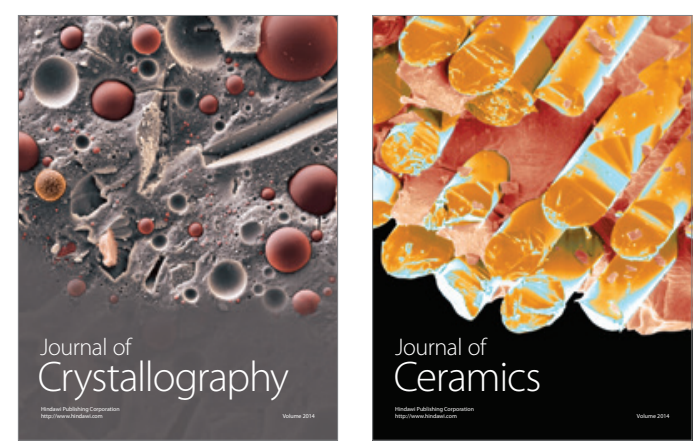
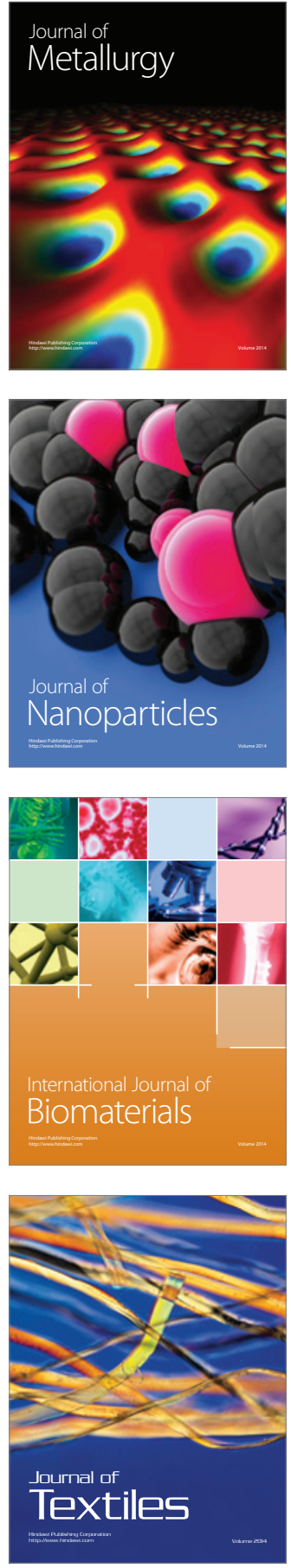